\title{
Calculation of Ultimate Bearing Capacity of Pile Foundations of Highway Bridges under the Coupling of Steep Slope and Karst
}

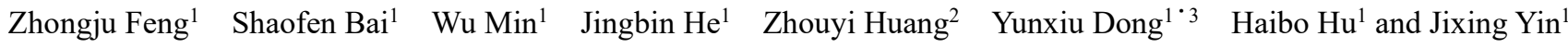 \\ ${ }^{1}$ School of Highway, Chang'an University, Xi'an 710064, China \\ ${ }^{2}$ Wenshan Guangna Expressway Investment Construction Development,Company Limited, Wenshan 663000,China \\ ${ }^{3}$ School of Civil Engineering, Longdong University, Qingyang 745000, China
}

\begin{abstract}
In order to study the influence of steep slope-karst coupling on the vertical bearing characteristics of pile foundation, the orthogonal simulation tests of pile foundation under 4 different roof thickness and 5 different slope are carried out by using Marc finite element software, and the correction coefficient of vertical partial bearing capacity of pile foundation according to roof thickness and slope is put forward. The test results show that when the thickness of the roof is more than 3 times the pile diameter, the ultimate bearing capacity of the pile foundation tends to be stable, and the value is about $19 \%$ when the slope is $45^{\circ}$; the ultimate bearing capacity of the pile foundation decreases gradually with the increase of the slope, and the reduction reaches $29.83 \%$ when the slope is greater than $45^{\circ}$. According to the calculation results, the variation law of vertical partial bearing capacity of pile foundation is analyzed, and the calculation formula of standard value of vertical ultimate bearing capacity of pile foundation in steep slope karst area considering both roof thickness and slope is put forward, and the correction coefficients $\alpha_{i}$ and $\beta$ are put forward.
\end{abstract}

\section{Research background}

With the continuous construction of China's highway network, karst strata and passing through steep slopes are becoming more and more common in engineering, and the requirements for the bearing capacity of pile foundation are getting higher and higher. Many scholars have conducted in-depth studies on the influence of karst caves on the bearing capacity of pile foundations and the effects of different treatment measures in karst caves[1-4]. For the underlying karst pile foundation, Zhao Minghua et al.[5] put forward a method to determine the bearing capacity of the rock-socketed pile in the karst area and the safe thickness of the roof of the underlying karst cave according to the instability and failure conditions of the roof of the karst cave under the rock-socketed pile in the karst area. Zhang Huile et al.[6-7] classified the failure modes of rock-socketed piles in karst area under different influencing factors into four types: punching failure, collapse failure in caving area, fan-shaped plastic zone failure and tearing failure, and put forward a series of formulas for the design of rock-socketed piles in karst area under different failure modes. Feng Zhongju et al.[8] analyzed the vertical ultimate bearing capacity of pile foundation with different gully slope and different pile length, and obtained the change law of pile axial force and pile side friction resistance. And combined with the analysis results, the relevant engineering and technical suggestions are put forward. Combined with the engineering geological characteristics of the steep slope of the western loess gully terrain, Luan Juan et al.[9] calculated and analyzed the influence of the steep slope of the loess gully topography on the bearing capacity of the pile foundation.

At present, there are many studies on the influence of karst or steep slope on the vertical ultimate bearing capacity of pile foundation at home and abroad, but there are few studies on the bearing capacity characteristics of pile foundation under the coupling action of karst and steep slope. The current code has not clearly defined the method to determine the bearing capacity of pile foundation in steep slope karst area. Based on the solid project of Guang Na Expressway in Yunnan Province, this paper uses Marc finite element software to design orthogonal numerical simulation test, systematically studies the influence of roof thickness and steep slope on the bearing characteristics of pile foundation, and puts forward the partial bearing capacity correction coefficient according to the calculation results, which has certain theoretical significance and engineering application value for further perfecting the current design code of pile foundation in steep slope karst area. 


\section{Orthogonal Simulation Test.}

\subsection{Constitutive Model and its Correctness Verification.}

In this paper, Marc finite element software is selected to design orthogonal simulation test for practical engineering simulation. In this test, the linear elastic constitutive model is used for the pile, and the elastic-plastic constitutive model is used for rock and soil, and the design is carried out according to the Mohr-Coulomb yield criterion. According to the field measured data and empirical values, the numerical simulation material parameters shown in Tab. 1 are obtained. First of all, in order to verify its correctness, a model of flat slope $\left(0^{\circ}\right)$ without karst cave is established, in which the pile diameter is $2 \mathrm{~m}$, the pile length is $24 \mathrm{~m}$, the upper cover soil is $28 \mathrm{~m}$ thick, the lower stroke limestone is $23.5 \mathrm{~m}$ thick, and the rock-socketed depth of the pile foundation is $1.5 \mathrm{~m}$. The solid model is shown in Fig. 1. In order to simulate the actual situation, the pile foundation is loaded vertically and graded until the pile is destroyed. The P-S curve of pile foundation is shown in Fig. 2.

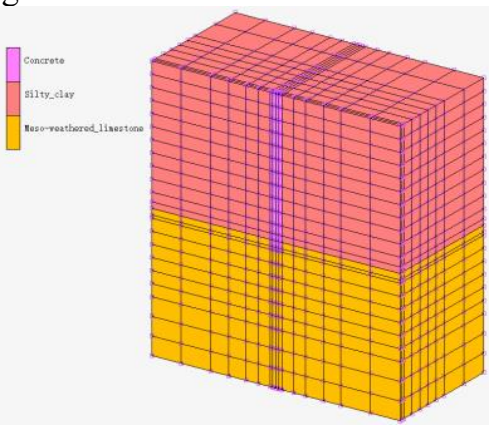

Figure 1.Internal sectional view of the model.

Table 1. Numerical simulation of material parameters

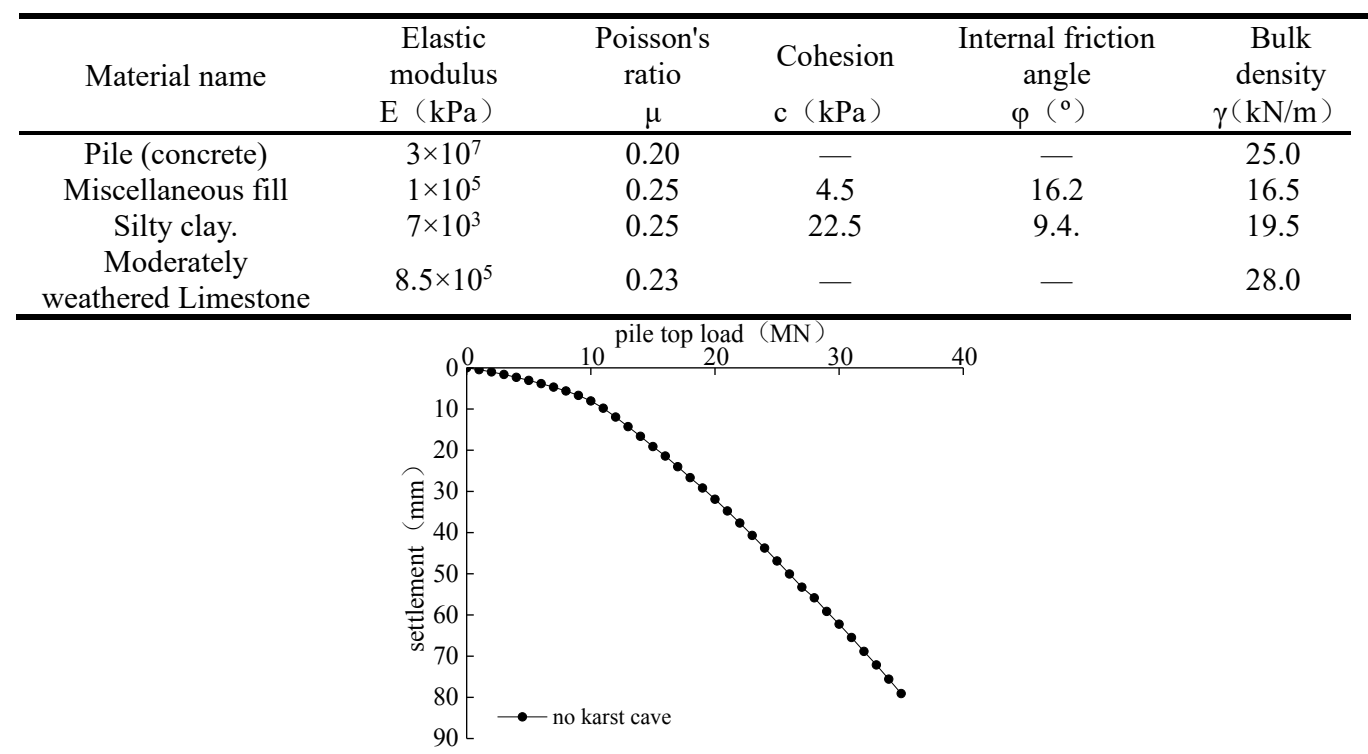

Figure 2. P-S curve of pile foundation without karst cave $0^{\circ}$

It can be seen from Fig. 2 that the P-S curve of numerical simulation is slowly changing, and the ultimate bearing capacity takes the corresponding load value of $40 \mathrm{~mm}$ settlement, that is, $22.77 \mathrm{MN}$. Code for Design of Foundations and Foundations of Highway Bridges and Culverts (JTG D63-2007) [10] stipulates:

Standard value of ultimate bearing capacity of bored cast-in-place pile:

$$
\left[R_{a}\right]=Q_{s k}+Q_{p k}=u \sum_{i=1}^{n} q_{s i k} l_{i}+A_{p} q_{p k}
$$

In formula (1), $u$ is the circumference of the pile; $l_{i}$ is the thickness of each soil layer around the pile; $q_{s i k}$ the standard value of the ultimate lateral friction corresponding to $l_{i}$ each soil layer and the side of the pile, $A_{p}$ is the cross-sectional area of the pile end; $q_{\mathrm{pk}}$ the standard value of the resistance of the pile end.

According to the field measured geological prospecting report and the above formula (1), it is calculated that the ultimate bearing capacity of pile foundation without karst cave and flat slope $\left(0^{\circ}\right)$ is $22827.8 \mathrm{kN}$, while the ultimate bearing capacity obtained by numerical simulation is $22773 \mathrm{kN}$, which is $54.8 \mathrm{kN}$ different from the theoretical value, and the error is only $0.24 \%$. It shows that the model and parameters used in this simulation test are reliable, the method is feasible, 
and the result is credible.

\subsection{Numerical simulation scheme.}

The karst development area of steep slope has complex geology and bad environment, and the construction of pile foundation is often disturbed by many factors, among which steep slope and karst are the key factors. This paper mainly discusses the influence of the thickness of karst cave roof and the slope of steep slope on the vertical bearing characteristics of pile foundation. In order to fully reflect the actual working conditions in the field, 4 kinds of representative roof thickness (h) and 5 kinds of slope (r) are selected for orthogonal simulation test. The test scheme is shown in Tab. 2.

Table 2. Numerical test scheme

\begin{tabular}{cccccc}
\hline $\begin{array}{c}\text { Pile diameter } \\
\mathrm{D}(\mathrm{m})\end{array}$ & $\begin{array}{c}\text { Pile length } \mathrm{L} \\
(\mathrm{m})\end{array}$ & Slope $r\left({ }^{\circ}\right)$ & $\begin{array}{c}\text { Cave height } \\
\mathrm{H}(\mathrm{m})\end{array}$ & $\begin{array}{c}\text { Karst cave span } \\
\mathrm{L}(\mathrm{m} \times \mathrm{m})\end{array}$ & $\begin{array}{c}\text { Roof thickness } \\
h(\mathrm{~m})\end{array}$ \\
\hline & & & & $2(1 \mathrm{D})$ \\
2 & 24 & $0,30,45,60,75$ & 4 & $6 \times 6$ & $4(2 \mathrm{D})$ \\
& & & & $6(3 \mathrm{D})$ \\
$8(4 \mathrm{D})$
\end{tabular}

\section{Analysis of the influence of roof thickness and slope on the bearing characteristics of pile foundation.}

\subsection{Analysis of influence degree of roof thickness.}

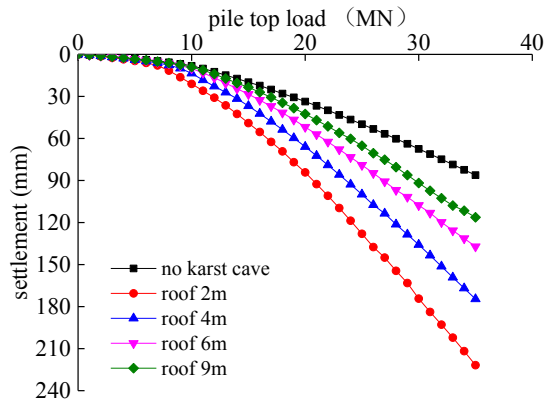

Figure 3 P-S curve of different roof thickness at $r=45^{\circ}$

As can be seen from Fig. 3, when the slope of the steep slope is constant, the ultimate bearing capacity of the pile foundation decreases with the decrease of the roof thickness. The reduction of bearing capacity is as follows: $\partial=\left|\frac{P_{j}-P_{0}}{P_{0}}\right|$, in the formula, $P_{j}$ is the ultimate bearing capacity of pile foundation under different roof thickness, and $P_{0}$ is the corresponding ultimate bearing capacity of pile foundation without karst cave. According to the numerical simulation results, the ultimate bearing capacity and reduction of pile foundation with different roof thickness shown in Fig. 4 are compared.

As can be seen from Fig. 3 to Fig. 4, when the roof thickness of karst cave changes from 4D to 1D at the same slope, the settlement value corresponding to the same load increases gradually with the decrease of roof thickness, and the ultimate bearing capacity of pile foundation decreases gradually with the decrease of roof thickness. when the slope is $45^{\circ}$, the ultimate bearing capacity of pile foundation with different roof thickness
The simulation test is carried out by considering the single variable method. For the slowly varying P-S curve, the corresponding load is the ultimate bearing capacity when the $40 \mathrm{~mm}$ settlement is taken. When the slope is fixed at $45^{\circ}$, the load-settlement of the pile foundation varies with the roof thickness as shown in Fig. 3.

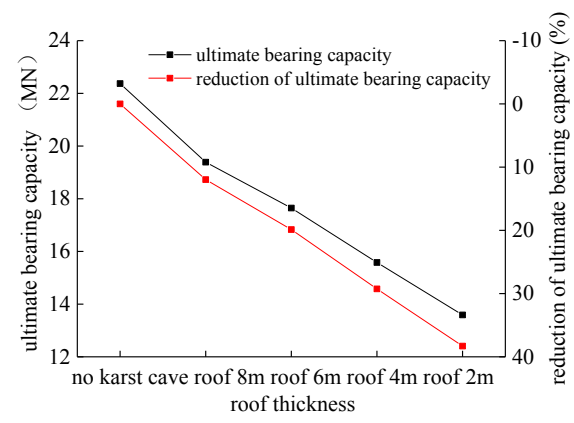

Figure 4 The reduction of ultimate bearing capacity of different roof thickness at $r=45^{\circ}$

is lower than that without karst cave by $11.97 \%, 19.88 \%$ and $29.26 \%$, respectively. $38.30 \%$, when the roof thickness is $3 \mathrm{D}(6 \mathrm{~m})$, the amplitude reduction curve appears a turning point, and the degree of reduction changes, that is, 3D is the limit of the influence of roof thickness on the ultimate bearing capacity of pile foundation. When the roof thickness is more than $3 \mathrm{D}$, the reduction is weaker, and when it is less than $3 \mathrm{D}$, the reduction is stronger, so it is considered that the maximum range of influence of underlying karst and other bad geology on pile foundation is 3 times the pile diameter. Continuing to increase the roof thickness has little effect on the ultimate bearing capacity of pile foundation, and the result is also in line with the range of safe roof thickness proposed by Zhao Minghua et al.[7-9].

\subsection{Slope influence degree analysis.}

When the thickness of roof is constant, the variation of load-settlement of pile foundation with slope is shown in Fig. 5, and the ultimate bearing capacity and reduction of 
pile foundation with different slope are shown in Fig. 6 . The ultimate bearing capacity and reduction of other roof

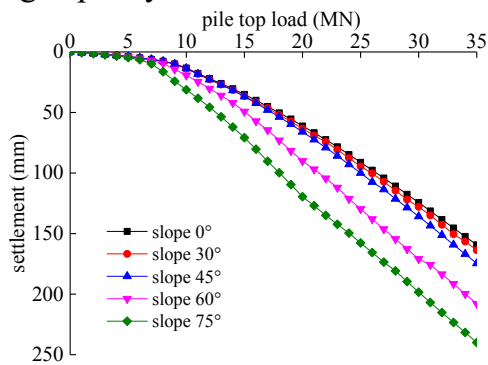

Figure 5.P-S curve of different slopes at $h=4 \mathrm{~m}$ thickness under the change of slope are shown in Tab. 3.

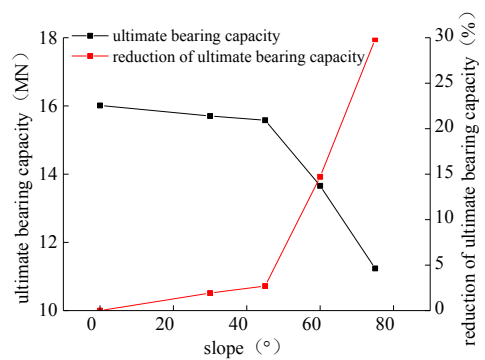

Figure 6.The reduction of ultimate bearing capacity of different slopes at $h=4 \mathrm{~m}$

Table 3. Ultimate bearing capacity and its reduction of different roof thickness under the change of slope

\begin{tabular}{|c|c|c|c|c|c|c|c|c|c|c|}
\hline \multirow{2}{*}{$\mathrm{r}^{\circ}{ }^{\left({ }^{\circ}\right)}$} & \multicolumn{2}{|c|}{ No karst cave } & \multicolumn{2}{|c|}{$2(1 \mathrm{D})$} & \multicolumn{2}{|c|}{$4(2 D)$} & \multicolumn{2}{|c|}{$6(3 D)$} & \multicolumn{2}{|c|}{$8(4 D)$} \\
\hline & $\begin{array}{c}P_{j} \\
(\mathrm{MN})\end{array}$ & $\begin{array}{c}\Delta P_{j} / P_{0} \\
(\%)\end{array}$ & $\begin{array}{c}P_{j} \\
(\mathrm{MN})\end{array}$ & $\begin{array}{c}\Delta P_{j} / P_{0} \\
(\%)\end{array}$ & $\begin{array}{c}P_{j} \\
(\mathrm{MN})\end{array}$ & $\begin{array}{c}\Delta P_{j} / P_{0} \\
(\%)\end{array}$ & $\begin{array}{c}P_{j} \\
(\mathrm{MN})\end{array}$ & $\begin{array}{c}\Delta P_{j} / P_{0} \\
(\%)\end{array}$ & $\begin{array}{c}P_{j} \\
(\mathrm{MN})\end{array}$ & $\begin{array}{c}\Delta P_{j} / P_{0} \\
(\%)\end{array}$ \\
\hline 0 & 22.77 & 0 & 13.85 & 0 & 16.01 & 0 & 18.22 & 0 & 20.03 & 0 \\
\hline 30 & 22.37 & 1.76 & 13.64 & 1.52 & 15.70 & 1.93 & 17.85 & 2.06 & 19.62 & 2.03 \\
\hline 45 & 22.03 & 3.28 & 13.59 & 1.88 & 15.58 & 2.70 & 17.65 & 3.16 & 19.39 & 3.20 \\
\hline 60 & 19.18 & 15.78 & 11.97 & 13.55 & 13.66 & 14.71 & 15.35 & 15.77 & 16.90 & 15.62 \\
\hline 75 & 15.59 & 31.53 & 10.39 & 25.00 & 11.24 & 29.83 & 12.40 & 31.98 & 13.39 & 33.15 \\
\hline
\end{tabular}

It can be seen from Fig. 5, Fig. 6 and Tab. 3 that when the roof thickness is constant, the ultimate bearing capacity of pile foundation decreases with the increase of slope, and when the slope is greater than $45^{\circ}$, the decrease changes significantly with the slope. When the thickness of the roof is $4 \mathrm{~m}$, it can be seen from Fig. 3 that the greater the slope under the same load, the greater the vertical displacement of the pile and the greater the reduction. When the slope increases from flat slope $\left(0^{\circ}\right)$ to $75^{\circ}$, the ultimate bearing capacity of pile foundation is 16.01MN, $15.70 \mathrm{MN}, 15.58 \mathrm{MN}, 13.66 \mathrm{MN}$ and $11.24 \mathrm{mn}$ respectively, and the ultimate bearing capacity decreases by $0 \%, 1.93 \%, 2.70 \%, 14.71 \%$ and $29.83 \%$, respectively. The above results show that the key to the influence of the steep slope on the ultimate bearing capacity of the pile foundation is that the larger the slope is, the more serious the lack of rock and soil on the side of the pile is, which directly leads to the weakening of the friction resistance on the side of the pile, and then affects the ultimate bearing capacity of the pile foundation. When the slope is greater than $45^{\circ}$, the impact is more significant, with a reduction of $29.83 \%$. Therefore, in practical engineering, the impact of rock and soil loss on the bearing characteristics of pile foundation should be considered when the slope is greater than $45^{\circ}$.

\subsection{Analysis of the influence of roof thickness and slope on the lateral resistance and end resistance of pile foundation.}

When the roof thickness changes, the pile tip resistance and pile side resistance and their specific gravity of the ultimate bearing capacity of pile foundation under different slopes are shown in Fig. 7, Fig. 8 and Tab. 4. $P_{c 1}$ and $P_{c 2}$ in Tab. 4 are the pile side friction values corresponding to soil layer 1 (silty clay) and soil layer 2 (moderately weathered limestone), respectively.

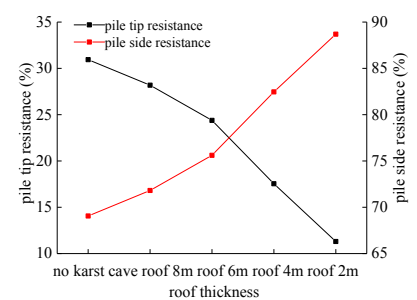

(b) Side resistance ratio curve of pile tip resistance

(a) Pile tip resistance curve

Figure 7 Load-bearing characteristic curve of different roof thickness at $r=45^{\circ}$ 

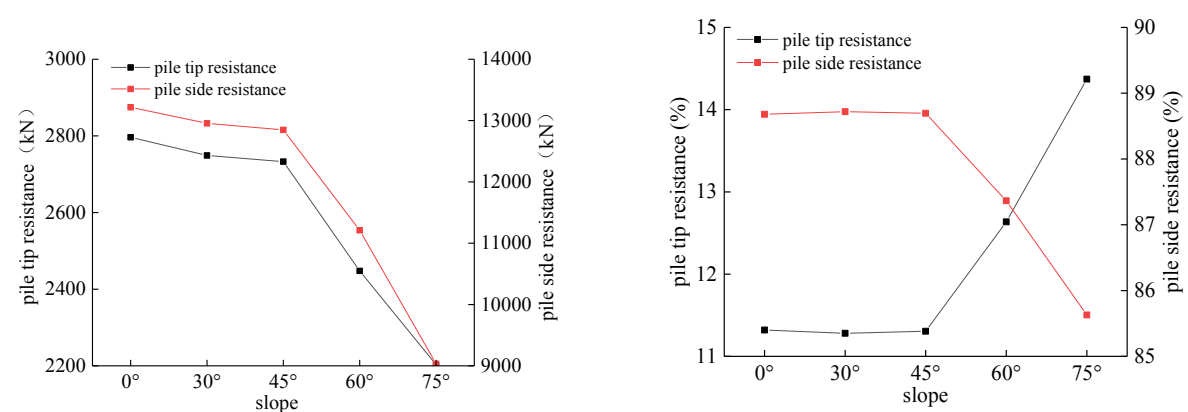

(a) Pile tip resistance curve

(b) Side resistance ratio curve of pile tip resistance

Figure 8 Load-bearing characteristic curves of different slopes at $h=4 \mathrm{~m}$

Table 4. Distribution of pile tip resistance and pile side friction resistance under different roof thickness

\begin{tabular}{|c|c|c|c|c|c|c|}
\hline \multirow{2}{*}{ Slope $r\left({ }^{\circ}\right)$} & \multirow{2}{*}{$\begin{array}{l}\text { Load bearing } \\
\text { characteristics }\end{array}$} & \multicolumn{5}{|c|}{ Roof thickness $h(\mathrm{~m})$} \\
\hline & & No karst cave & $8(4 \mathrm{D})$ & $6(3 \mathrm{D})$ & $4(2 \mathrm{D})$ & $2(1 \mathrm{D})$ \\
\hline \multirow{5}{*}{0} & $P_{c 1}(\mathrm{kN})$ & 11193 & 10516 & 10023 & 9389 & 9226 \\
\hline & $P_{c 2} \quad(\mathrm{kN})$ & 4544 & 3859 & 3768 & 3828 & 3056 \\
\hline & $\sum P_{c i} / P \quad(\%)$ & 69.1 & 71.8 & 75.7 & 82.5 & 88.7 \\
\hline & $P_{d}(\mathrm{kN})$ & 7036 & 5654 & 4433 & 2796 & 1568 \\
\hline & $P_{d} / P \quad(\%)$ & 30.9 & 28.2 & 24.3 & 17.5 & 11.3 \\
\hline \multirow{5}{*}{30} & $P_{c 1}(\mathrm{kN})$ & 10916 & 10261 & 9809 & 9200 & 9066 \\
\hline & $P_{c 2}(\mathrm{kN})$ & 4561 & 3827 & 3693 & 3756 & 3035 \\
\hline & $\sum P_{c i} / P \quad(\%)$ & 69.2 & 71.8 & 75.6 & 82.5 & 88.7 \\
\hline & $P_{d} \quad(\mathrm{kN})$ & 6894 & 5534 & 4347 & 2749 & 1539 \\
\hline & $P_{d} / P \quad(\%)$ & 30.8 & 28.2 & 24.4 & 17.5 & 11.3 \\
\hline \multirow{5}{*}{45} & $P_{c 1}(\mathrm{kN})$ & 10844 & 10207 & 9764 & 9161 & 9025 \\
\hline & $P_{c 2}(\mathrm{kN})$ & 4367 & 3716 & 3580 & 3687 & 3028 \\
\hline & $\sum P_{c i} / P \quad(\%)$ & 69.1 & 71.8 & 75.6 & 82.5 & 88.7 \\
\hline & $P_{d} \quad(\mathrm{kN})$ & 6815 & 5465 & 4304 & 2733 & 1536 \\
\hline & $P_{d} / P \quad(\%)$ & 30.9 & 28.2 & 24.4 & 17.5 & 11.3 \\
\hline \multirow{5}{*}{60} & $P_{c 1}(\mathrm{kN})$ & 9403 & 8845 & 8520 & 7990 & 7945 \\
\hline & $P_{c 2} \quad(\mathrm{kN})$ & 3882 & 3281 & 3063 & 3220 & 2515 \\
\hline & $\sum P_{c i} / P \quad(\%)$ & 69.3 & 71.7 & 75.5 & 82.1 & 87.4 \\
\hline & $P_{d}(\mathrm{kN})$ & 5894 & 4774 & 3767 & 2448 & 1513 \\
\hline & $P_{d} / P \quad(\%)$ & 30.7 & 28.3 & 24.5 & 17.9 & 12.6 \\
\hline \multirow{5}{*}{75} & $P_{c 1}(\mathrm{kN})$ & 7700 & 7169 & 6931 & 6677 & 6753 \\
\hline & $P_{c 2} \quad(\mathrm{kN})$ & 3051 & 2394 & 2360 & 2357 & 2141 \\
\hline & $\sum P_{c i} / P \quad(\%)$ & 69.0 & 71.4 & 75.0 & 80.4 & 85.6 \\
\hline & $P_{d} \quad(\mathrm{kN})$ & 4841 & 3827 & 3105 & 2203 & 1493 \\
\hline & $P_{d} / P \quad(\%)$ & 31.0 & 28.6 & 25.0 & 19.6 & 14.4 \\
\hline
\end{tabular}

As can be seen from Fig. 7, Fig.8 and Tab. 4, when the slope is constant, the proportion of pile side resistance decreases and the proportion of pile tip resistance increases with the increase of roof thickness. Taking the slope $\mathrm{r}=45^{\circ}$ as an example, when the roof thickness $\mathrm{h}$ increases from $2 \mathrm{~m}$ to $8 \mathrm{~m}$ and there is no karst cave, the proportion of pile side resistance in the total ultimate bearing capacity of pile foundation decreases from $88.7 \%$ to $69.1 \%$. The proportion of pile tip resistance in the total ultimate bearing capacity of pile foundation increased from $11.3 \%$ to $30.9 \%$. As a result, it can be seen that when the thickness of the roof decreases gradually, the proportion of pile side resistance increases gradually, and the bearing characteristics of pile foundation gradually change from friction end-bearing pile to friction pile. When the thickness of the roof is constant, the proportion of pile side resistance decreases and the proportion of pile tip resistance increases with the increase of slope, and the change degree of pile foundation parameters increases significantly when the 
slope $r>45^{\circ}$. Taking the roof thickness $h=4 m$ as an example, when the slope increases from flat slope $\left(0^{\circ}\right)$ to $75^{\circ}$, the variation range of pile side resistance ratio is $80.4 \%-82.5 \%$, and the reduction range of pile tip resistance is $17.5 \%-19.6 \%$. The reason for this phenomenon is that the variation rules of pile side resistance and pile tip resistance are similar under different slopes or different roof thickness. when the slope increases and the roof thickness decreases, the partial bearing capacity of pile foundation tends to decrease. When the rock-socketed depth and roof thickness are constant, the degree of lack of rock and soil on the side of the pile increases with the increase of the slope, the load at the top of the pile is mainly borne by the resistance at the end of the pile, and the exertion of the resistance on the side of the pile decreases significantly, indicating that the slope has an important influence on the vertical bearing characteristics of bridge pile foundation in the karst development area of steep slope. when the slope is greater than $45^{\circ}$, the influence of rock and soil loss on the bearing characteristics of pile foundation should be considered. When the rock-socketed depth and slope are constant, with the increase of the roof thickness, the upper load is still mainly borne by the pile side resistance, but at this time, the pile side resistance proportion gradually decreases, and the pile tip resistance gradually plays a role, when the roof thickness is more than 3 times the pile diameter, the proportion of partial bearing capacity tends to be stable, and it is of little significance to increase the vertical ultimate bearing capacity of pile foundation by increasing the thickness of roof.

\section{Revision of the formula for calculating the ultimate bearing capacity of pile foundation.}

The formula (1) in section 1.1 does not take into account the influence of steep slope and roof thickness. It can be seen from the above that the increase of steep slope directly affects the lack of soil on the side of pile, and then the lateral resistance of pile foundation is greatly reduced. When the slope is more than $45^{\circ}$, the decrease of pile side resistance increases significantly. With the increase of roof thickness, the proportion of pile tip resistance increases gradually, and when the roof thickness is more than 3 times of pile diameter, the increase of pile tip resistance is smaller and tends to be smooth. When considering the influence of slope and roof thickness at the same time, the standard value of vertical ultimate bearing capacity of single pile is calculated according to formula (2):

$$
\left[R_{a}\right]=Q_{s k}+Q_{p k}=\alpha_{i} u \sum_{i=1}^{n} q_{i k} l_{i}+\beta A_{p} q_{r}
$$

In formula (2), $\alpha_{i}$ and $\beta$ are the correction coefficients of ultimate bearing capacity of pile foundation of slope and roof thickness, respectively. The values are taken according to Tab. 5 and Tab. 6, and the correction coefficients can be selected by interpolation in other cases. $\alpha_{1}$ and $\alpha_{2}$ in Tab. 5 are the correction coefficients of pile side friction corresponding to soil layer 1 (silty clay) and soil layer 2 (moderately weathered limestone), respectively.

Table 5. Correction coefficient of slope to ultimate bearing capacity of pile foundation

\begin{tabular}{|c|c|c|c|c|c|c|}
\hline \multicolumn{2}{|c|}{$r\left(^{\circ}\right)$} & 0 & 30 & 45 & 60 & $\geq 75$ \\
\hline \multirow{2}{*}{$\begin{array}{c}\text { No karst } \\
\text { cave }\end{array}$} & $\alpha_{1}$ & 1 & 0.975 & 0.969 & 0.840 & 0.688 \\
\hline & $\alpha_{2}$ & 1 & 1.004 & 0.961 & 0.854 & 0.671 \\
\hline \multirow{2}{*}{$1 \mathrm{D}$} & $\alpha_{1}$ & 1 & 0.983 & 0.978 & 0.861 & 0.732 \\
\hline & $\alpha_{2}$ & 1 & 0.993 & 0.991 & 0.823 & 0.701 \\
\hline \multirow{2}{*}{$2 \mathrm{D}$} & $\alpha_{1}$ & 1 & 0.980 & 0.976 & 0.851 & 0.711 \\
\hline & $\alpha_{2}$ & 1 & 0.981 & 0.963 & 0.841 & 0.616 \\
\hline \multirow{2}{*}{$3 \mathrm{D}$} & $\alpha_{1}$ & 1 & 0.979 & 0.974 & 0.850 & 0.692 \\
\hline & $\alpha_{2}$ & 1 & 0.980 & 0.950 & 0.813 & 0.626 \\
\hline \multirow{2}{*}{$4 \mathrm{D}$} & $\alpha_{1}$ & 1 & 0.976 & 0.971 & 0.841 & 0.682 \\
\hline & $\alpha_{2}$ & 1 & 0.992 & 0.963 & 0.850 & 0.620 \\
\hline
\end{tabular}

Table 6. Correction coefficient of roof thickness to ultimate bearing capacity of pile foundation

\begin{tabular}{cccccc}
\hline \multicolumn{1}{c}{ N(m) } & $\begin{array}{c}\text { No karst } \\
\text { cave }\end{array}$ & $8(4 \mathrm{D})$ & $6(3 \mathrm{D})$ & $4(2 \mathrm{D})$ & $\leq 2(1 \mathrm{D})$ \\
\hline $0^{\circ}$ & 1 & 0.804 & 0.630 & 0.397 & 0.223 \\
$30^{\circ}$ & 1 & 0.803 & 0.631 & 0.399 & 0.223 \\
$45^{\circ}$ & 1 & 0.802 & 0.632 & 0.401 & 0.225 \\
$60^{\circ}$ & 1 & 0.810 & 0.639 & 0.415 & 0.257 \\
$75^{\circ}$ & 1 & 0.791 & 0.641 & 0.455 & 0.308 \\
\hline
\end{tabular}

\section{Conclusion.}

By using the finite element software Marc, combined with the field measured soil parameters, four representative roof thicknesses and five steep slope slopes are selected to design orthogonal numerical simulation tests, and the correction coefficient of ultimate 
bearing capacity of pile foundation under the coupling action of steep slope and karst is put forward. the vertical bearing characteristics of pile foundation in steep slope karst area are studied systematically, and the following conclusions are drawn.

(1) when the steep slope is constant, the ultimate bearing capacity of pile foundation increases with the increase of roof thickness, and the bearing capacity tends to be stable when the roof thickness is more than 3 times the pile diameter. Therefore, it is considered that the maximum "limit" of the influence of roof thickness on the ultimate bearing capacity of pile foundation is 3 times of pile diameter.

(2) when the roof thickness is constant, the ultimate bearing capacity of pile foundation decreases with the increase of slope, and when the slope is greater than $45^{\circ}$, the decrease changes significantly with slope, so in practical engineering, when the slope is greater than $45^{\circ}$, the influence of rock and soil loss on the bearing characteristics of pile foundation should be considered.

(3) when the slope is constant, the proportion of pile side resistance decreases and the proportion of pile tip resistance increases with the increase of roof thickness. Taking the slope $r=45^{\circ}$ as an example, when the roof thickness $h$ increases from $2 \mathrm{~m}$ to $8 \mathrm{~m}$ and there is no karst cave, the proportion of pile side resistance decreases from $88.7 \%$ to $69.1 \%$, and the proportion of pile tip resistance increases from $11.3 \%$ to $30.9 \%$. When the thickness of the roof is constant, with the increase of the slope, the proportion of pile side resistance gradually decreases and the proportion of pile tip resistance gradually increases. Taking the roof thickness $h=4 \mathrm{~m}$ as an example, when the slope increases from flat slope $\left(0^{\circ}\right)$ to $75^{\circ}$, the variation range of pile side resistance ratio is $80.4 \%-82.5 \%$, and the reduction range of pile tip resistance is $17.5 \%-19.6 \%$, and when the slope is greater than $45^{\circ}$, the ultimate bearing capacity of pile foundation, pile side resistance, pile tip resistance and other changes are significantly increased.

(4) compared with the thickness of the roof, the increase of the slope of the steep slope will directly reduce the lateral resistance of the pile foundation. However, with the increase of the thickness of the roof, the proportion of the resistance of the pile tip increases gradually, so by modifying the partial bearing capacity of the pile foundation, the formula for calculating the ultimate bearing capacity of pile foundation in karst area of steep slope is obtained.

\section{References:}

1. Feng Z.J., Wang F.C., Su H.Z., etc. (2017) Centrifugal model test on the influence of loess cave on vertical bearing characteristics of bridge pile foundation $[\mathrm{J}]$. Journal of Chang'an University: Natural Science Edition. 37 (02): 35-44.

2. Dong Y.X., Feng Z.J., Hao Y.M., Yao H.S., Zhang X.W., Xie F.G. (2018) Bearing capacity test and reasonable rock-socketed depth of bridge pile foundation in karst area [J]. Journal of Traffic and Transportation Engineering, 18 (06): 27-36.
3. Feng Z.J., Dong Y.X., Wen J.Q, Hu H.B, Li X.X, He J.B. (2019) Calculation method of pile foundation bearing capacity of highway bridge in Ningbo deep soft foundation area $[\mathrm{J}]$. Journal of Tianjin University: Natural Science and Engineering Technology Edition, 52 (S1): 16-22.

4. Feng Z.J, Hu H.B, Dong Y.X, Feng Kai, Li S.J, He J.B, Zhao Y.W. (2019) Indoor simulation test for reducing negative friction of pile foundation $[\mathrm{J}]$. Journal of Geotechnical Engineering, 41 (S2): 45-48.

5. Zhao M.H, Jiang C., Cao W.G. (2007) Study on bearing capacity of rock-socketed pile and safe thickness of underlying karst cave roof in karst area [J]. Journal of Geotechnical Engineering, (11): $1618-1622$.

6. Zhang Z.H., Zhang H.L, Ma Lin, Sun Y.X. (2013) Discussion on failure mode and engineering design of rock-socketed piles in karst area [J]. Journal of Rock Mechanics and Engineering, 32 (S2): 4130-4138.

7. Sun Y.X, Zhang Z.H, Zhang H.L. (2013) Sensitivity analysis of parameters affecting pile foundation stability in karst area [J]. Journal of Underground Space and Engineering, 9 (02): 297-303.

8. Feng Z.J, Wang H., Wei J., Gao X., Jia Y.W, Zhang X. (2015) Model experimental study on vertical bearing characteristics of pile foundation of loess gully slope bridge [J]. Journal of Geotechnical Engineering, 37 (12): 2308-2314.

9. Luan J., Hao X.W., Zhao B.J. (2016) Influence of steep slope of loess gully topography on bearing capacity of pile foundation [J]. Journal of Chang'an University: Natural Science Edition, 36 (06): 62-68.

10. JTG D63-2007 Code for Design of Foundation and Foundation of Highway Bridges and Culverts [S]. 